\title{
Unit nonresponse at the firm level: a cross-border analysis using the IAB-ReLOC data
}

\author{
Veronika Hecht ${ }^{*}$ (D, Nicole Litzel and Johannes Schäffler
}

\begin{abstract}
The labour market effects of foreign direct investments (FDI) are a topic of constant interest. However, research progress is hindered as most datasets applied in research on this topic suffer from selectivity with respect to firm size. To overcome this deficiency a unique dataset that covers the total population of German firms with FDI in the Czech Republic and their Czech affiliates has been created: the IAB-ReLOC data. Based on this dataset, two points of high relevance are addressed in this paper. First, by presenting the generation process of this unique dataset the paper wants to provide guidance for similar cross-border data compilation projects and for researchers working with the data. Second, new insights on unit nonresponse in a firm-level survey are revealed. Based on multi-level logit models, the influence of firm and interviewer characteristics and of FDI features on survey participation is analysed. The main result is that apart from firm size and interviewer involvement, the response behaviour is related to the distance to the German-Czech border and to the strength of the cross-border relationship. What concerns the two latter characteristics, differences between German and Czech firms are identified.
\end{abstract}

Keywords: Unit nonresponse, Cross-border survey, Firm-level survey, FDI, Germany, Czech Republic JEL Classification: C81, C83, F23

\section{Introduction}

With the ongoing globalisation, foreign direct investment (FDI) has gained more and more importance over the last decades. The enormous growth in FDI flows (Helpman 2006) is also reflected in a high research interest. Various questions related to FDI are subject to theoretical considerations as well as empirical studies (for an overview see Paul and Singh 2017). Prominent topics in FDI research are, among others, the role of firm heterogeneity in the internationalisation process of firms (see Helpman et al. 2004, for example), the motives for FDI (Alfaro and Charlton 2009) and the location choice of FDI (for an overview see Jones 2017). Furthermore, many studies deal with the relationship between FDI and economic growth (a current example is Bermejo Carbonell and Werner 2018), the spillovers between FDI

*Correspondence: veronika.hecht@iab.de

Regional Labour Markets, IAB-Institute for Employment Research,

Regensburger Str. 104, 90478 Nuremberg, Germany and domestic firms and the mechanisms behind these (Nicolini and Resmini 2010). More recently, the relationship between FDI and innovation is analysed (Wang et al. 2016, for instance). Finally, the labour market effects of FDI are a topic of constant interest (Lechevalier 2015). In developed countries, people fear job losses and wage reductions due to FDI and the associated relocation of production units to foreign countries. However, empirical evidence on the labour market effects of FDI is mixed (Crinò 2009). For Germany, the results of empirical studies on the employment effects of FDI range from negative effects over no significant effect to positive effects (see Pflüger et al. 2013; Schäffler and Moritz 2018). One short-coming of these studies is that they are based on selective datasets in which small and medium-sized firms are underrepresented. Although especially the largest and most productive firms engage in FDI (Helpman et al. 2004), there are some investment regions that are attractive investment targets for smaller firms, too. For German investors, the Central and Eastern European 
countries (CEECs) constitute due to the geographical proximity and the pronounced wage cost differential a prime example in this regard (Buch et al. 2005).

To contribute to the closure of these research gaps, the German Institute for Employment Research (IAB) has in collaboration with the Czech Center for Economic Research and Graduate Education (CERGE-EI) established a cross-national dataset that covers the total population of German firms that were involved in at least one Czech firm in 2010 as well as the total population of the Czech affiliates. Furthermore, for both countries a reference group that has no financial connections to foreign firms is included in the dataset. To get more detailed insights into the structures of multinational firms, the firms have been addressed within the IAB-ReLOC ${ }^{1}$ survey. In addition, via a record linkage method, the German parent companies have been linked to the employment data of the IAB. Although initially created to investigate the labour market effects of FDI, in this paper, the IABReLOC dataset is used to get insights into another crucial topic in social sciences: unit nonresponse, i.e. in the unwillingness of firms to participate in a survey.

Although data collection and availability have rapidly increased within the last decade as reflected in the discussions on big data (Japec et al. 2015), surveys are still an important instrument in social and economic research and will be necessary in the future (Wiengarten and Zwick 2018). However, the response rates in household but also in firm-level surveys have steadily been decreasing over the last decades (Rogelberg and Stanton 2007) or the effort to maintain their level has increased (Groves 2006; Petroni et al. 2004). The decline has been particularly pronounced for voluntary surveys and less so for mandatory surveys. Yet, especially these voluntary surveys are important data sources for research in social and economic sciences. A problem arises if non-participation in the survey is not random but if firms self-select into participating in the survey. This may lead to biased results. However, in many studies it is difficult to assess if and in what regard participating firms differ from nonparticipating firms as information is only available for respondents. The great advantage of the IAB-ReLOC dataset is that administrative data is available for both participating and non-participating firms. These data can be used to address the question if and in what regard participating and non-participating firms differ and, thus, to contribute to a better understanding of unit nonresponse in a firm-level survey. A special feature is that the nonresponse behaviour of German and Czech firms can be compared.

${ }^{1}$ ReLOC stands for 'Research on Locational and Organisational Change'.
The contribution of the study to the existing literature is threefold. First, the description of the data compilation process of the IAB-ReLOC data can support the creation of similar cross-national datasets. Second, the linkage of the survey data to administrative data allows an in-depth analysis of unit nonresponse in a firm-level survey. Special is that besides interviewer and firm characteristics also information on the international involvement of the firm is included in the analysis. The third contribution of this paper relates to the cross-border nature of the IABReLOC dataset: The factors provoking unit nonresponse can be identified for both German and Czech firms. This allows an international comparison of the survey participation behaviour of German and Czech companies and gives, as required inter alia by Rogelberg and Stanton (2007), new insights into this field of research.

The estimation of multi-level logit models reveals that across all subgroups firm size is positively correlated to the nonresponse probability. With regards to the interviewer characteristics, older interviewers and better educated interviewers are more successful in recruiting respondents. Regarding the features of the FDI project, on both sides of the border, firms that are directly linked to a company from the neighbouring country show a lower probability for nonresponse. An interesting contrast is identified with respect to the location of the companies: While in Germany firms that are located closer to the border with the Czech Republic show a lower nonresponse probability, the opposite holds for the Czech Republic: Here, the nonresponse probability declines when the firm's distance to the German border rises. However, this does not hold for the border region.

The remainder of the paper is structured as follows: Sect. 2 describes the data compilation process. The definition of the research units is explained in Sect. 2.1 and the identification of the research units is highlighted in Sect. 2.2. Section 2.3 gives an overview of the IABReLOC survey, while in Sect. 2.4 a short description of the record linkage method that was applied to link the firm-level data to the administrative establishmentlevel data is given. Section 3 presents the nonresponse analysis. In Sect. 3.1, unit nonresponse is defined and a short overview of related literature is given. Section 3.2 refers to the selection of the explanatory variables. Section 3.3 gives a brief overview of the estimation method. In Sect. 3.4, the estimation results are presented and discussed. Section 4 concludes with a summary and an outlook to future research.

\section{The IAB-ReLOC data}

In the following paragraphs, details on the data generation process of the IAB-ReLOC data are provided. 


\subsection{Definition of research unit}

In the context of growing globalisation, companies split up their value-added chains and international linkages become more complex and dynamic. This complicates the analysis of the labour market effects of FDI as they may differ at different organisational levels of the same economic unit. As in previous studies the different organisational levels establishment, firm/company ${ }^{2}$ and corporate group are rather mixed up, much emphasis is put on an accurate definition of the research unit in the IAB-ReLOC data. This is not only important for a correct interpretation of the results but also for the interviewed units as they must know for which unit the required data should be given (Petroni et al. 2004; Willimack and Nichols 2010). The terms firm and company refer to a unit that is one legal entity. It can comprise more than one legally not independent establishment(s) at different locations. Companies can, furthermore, be linked to a corporate group that comprises firms that keep their legal independence.

As the decision if, how and where a foreign investment takes place is-mostly-taken at the firm level, the research unit is defined by the company in the IABReLOC data. In addition, the firm level allows to establish parallel structures in both countries. While in Germany there is both a company identifier and an establishment identifier, the latter does not in a comparable way exist in the Czech Republic. Thus, only by referring to the company level, data from both countries can be compared.

To analyse the labour market effects of offshoring, four groups of companies are included in the IAB-ReLOC data. In Germany, a group of multinational enterprises (MNEs) with FDI in the Czech Republic and a group of companies that are not engaged in FDI are distinguished. In the Czech Republic, the German affiliates are compared to a group of companies that have no foreign investor (see Table 1).

\subsection{Identification of research units}

The starting point for the data compilation process was the identification of the firms in the Czech MNE group, i.e. the Czech affiliates of German companies. To obtain a dataset containing the total population of German-Czech companies, we exploited three different sources. The first source was a dataset of the German-Czech Chamber of Industry and Commerce from the year 2008 (DeutschTschechische Industrie- und Handelskammer 2008) containing 3427 Czech companies with a direct German owner as well as Czech companies that were indirectly

\footnotetext{
2 The terms firm and company refer to the same organisational unit and are used interchangeably throughout this paper.
}

Table 1 Overview of research design

\begin{tabular}{|c|c|c|}
\hline & Czech Republic & Germany \\
\hline MNE group & $\begin{array}{l}\text { - Czech firms with German } \\
\text { equity holders ( } \geq 25 \%) \\
\text { - Subsidiaries of German } \\
\text { companies } \\
\Rightarrow 3875 \text { companies with } \\
\text { German parent company }\end{array}$ & $\begin{array}{l}\text { - Owners of the } 3875 \\
\text { Czech MNEs } \\
\Rightarrow 3406 \text { German firms } \\
\text { with Czech affiliate }\end{array}$ \\
\hline $\begin{array}{l}\text { Reference } \\
\text { group }\end{array}$ & $\begin{array}{l}\text { - Purely Czech-owned firms } \\
\Rightarrow 10,262 \text { companies }\end{array}$ & $\begin{array}{l}\text { German firms without } \\
\text { - FDI } \\
\text { - Foreign affiliated } \\
\text { company } \\
\text { - Indirect investment } \\
\text { abroad } \\
\Rightarrow 9768 \text { companies }\end{array}$ \\
\hline
\end{tabular}

Source: IAB-ReLOC data, authors' own illustration

linked to a German firm via a holding company located e.g. in the Netherlands, Luxembourg or Switzerland. The second dataset we exploited was a dataset of the commercial data provider Creditinfo. This dataset contained 186,365 active Czech firms (as at September 2009). Third, a dataset of the Czech commercial data provider Čekia ${ }^{3}$ (as at December 2009) was used. This dataset comprised information on 74,770 Czech companies obliged to publish balance sheet data. The information if a company had a German investor was derived from the Czech Commercial Register. This database contains a company identifier (IČO), the name and the address of the company andwhat was crucial for the construction of the ReLOC database-also the names and addresses of the owners. After exploiting all these sources, 3875 Czech companies with a German firm owning at least $25 \%$ of the capital have been identified. ${ }^{4}$ This number is significantly higher than in other datasets that are used in scientific research. For instance, the AMADEUS dataset of Bureau van Dijk contained 1150 and the MIDI dataset of the German Federal Bank 1000 Czech companies with German owner in 2011 (Hecht et al. 2013b). The German MNE group consists of the parent companies of the firms in the Czech MNE group and, consequently, builds on the Czech MNE group. As some German companies are engaged in more than one Czech firm, the German MNE group finally comprises 3406 firms (Schäffler 2014).

\footnotetext{
${ }^{3}$ The datasets Creditinfo (published by Creditinfo-Registr Kreditních Informací s.r.o.) and Čekia (published by Česká kapitálová informační agentura, a.s.) contain information on legal entities registered in the Czech Republic comprising, among others, information on location, industries and number of employees. By combining both datasets, we have tried to build a dataset containing all companies active on the Czech market.

4 Actually, 5700 Czech companies with a German owner have been identified. Among the investors were many private persons. From that group, only those Czech companies with a German sister company were eligible for the Czech MNE group.
} 
The Czech reference group consists of firms that are neither directly nor indirectly owned by a foreign company. This information was extracted from the Creditinfo dataset. The German reference group comprises firms without any direct or indirect foreign investment and without a foreign sister company. This sample was selected from a dataset of the commercial data provider 'Heins und Partner. ${ }^{5}$ To ensure that the firms in the MNE groups and in the reference groups were similar with respect to employment size and industry affiliation, stratified sampling regarding these two dimensions was applied.

\subsection{IAB-ReLOC survey}

To obtain detailed insights into the companies engaged in FDI and in the consequences of investing abroad, the identified companies were addressed in the IAB-ReLOC survey. Subject to the questionnaire was not only the employment and organisational structure of the firms but, for the MNEs, information on the motives for investing abroad and on the decision structures within the multinational company were collected (for more details see Hecht et al. 2013a).

To achieve the highest possible response rate, data was collected via paper and pencil interviews (PAPI), as direct contact between interviewers and respondents may result in a higher participation rate than in web or telephone surveys (Groves et al. 2009). When questions could not be answered at once, the PAPI questionnaire could be left at the firm and filled in later. This is also important for large firms where often more individuals are involved in answering a questionnaire (Willimack and Nichols 2010) and results in a reduction of item nonresponse (Ellguth et al. 2014). To reduce unit nonresponse, the questionnaire could be answered via telephone or mail if required by the respondents (Tomaskovic-Devey et al. 1994).

The ReLOC questionnaires are based on two wellestablished instruments: the questionnaire of the IAB Establishment Panel (see Fischer et al. 2009) and the questionnaire of CORIS (see Möller and Litzel 2008). For each of the four firm groups an adapted version of the questionnaire had to be developed in the questionnaire design process. This was done in a parallel approach (see Harkness et al. 2003) in coordination with the Czech project partners from CERGE-EI and the Chair of Sociology and Empirical Social Research at the University of

\footnotetext{
${ }^{5}$ The dataset contains information on all companies that actively operate on the German market. The dataset combines information of official registers (commercial register and register of cooperative societies) and of commercial data providers. The use of this commercial database for the compilation of the German reference group was necessary as the IAB establishment data do not contain any information on foreign involvement of firms. In addition, the linkage to the establishment data of the IAB (described in 2.4) had not been finished at that point in time.
}

Erlangen-Nuremberg. The aim was to equally create and formulate as many questions and items for Germany and the Czech Republic as possible. However, the differences in language, culture and social structure make it difficult to achieve equivalence (Smith 2003; Van de Vijver and Leung 1997). In this context, the instruments developed in a parallel way work better than sequentially developed ones due to numerous discussions and feedbacks within the international team (Harkness et al. 2003). Deviations between the German and the Czech versions were necessary due to institutional differences between the two labour markets. Special effort was put on the translation procedure as especially the translation of the questionnaire may result in severe problems regarding question content. While at the beginning an English master version of the questionnaire was used for discussion within the international team, a German master version was used after the pretest. The final questionnaires were translated from a specialist translator to Czech language, retranslated to German by another specialist and then compared and corrected by the research team. To assure that the questions and items work, pretests were conducted in both countries (see Hecht et al. 2013b).

The IAB-ReLOC survey was conducted in the period between September 2010 and March 2011 by TNS Infratest Sozialforschung in Germany and by TNS AISA in the Czech Republic. In both countries, the interviewers were native speakers to avoid communication problems and to counteract possible reservations with regards to crossborder surveys (Van de Vijver and Leung 1997). The contact to a firm was established via the highest-ranked person or her deputy. To raise the willingness to participate, the potential interview partners were provided with personalised recommendation letters of IAB (in Germany) and of CERGE-EI (in the Czech Republic) as well as of the German-Czech Chamber of Industry and Commerce (in both countries). In addition, confidentiality pledges were provided. After receiving the letter, a direct contact was established by the interviewer.

In Germany, 459 interviews were realised in the MNE group and 1285 companies were interviewed in the reference group. In the Czech MNE group, 474 companies were interviewed and 858 interviews were realised in the Czech reference group (see Table 2). This corresponds to adjusted response rates of $14.9 \%$ in the German MNE group, $18.5 \%$ in the German reference group, $12.9 \%$ in the Czech MNE group and 19.1\% in the Czech reference group (Hecht et al. 2013b).

\subsection{ReLOC linkage}

The data collected in the IAB-ReLOC survey is especially useful for analysing the motives for FDI, the organisational changes and the decision processes within the 
Table 2 Overview of number of cases

\begin{tabular}{|c|c|c|c|c|}
\hline & \multicolumn{2}{|c|}{ Germany } & \multicolumn{2}{|c|}{ Czech Republic } \\
\hline & MNEs & Non-MNEs & MNES & Non-MNEs \\
\hline Identified companies & 3406 & 9768 & 3875 & 10,262 \\
\hline Interviewed (ReLOC survey) & 459 & 1285 & 474 & 858 \\
\hline $\begin{array}{l}\text { Linked to IAB employment } \\
\text { statistics }\end{array}$ & 2421 & 7566 & - & - \\
\hline $\begin{array}{l}\text { Information available from } \\
\text { Czech commercial datasets }\end{array}$ & - & - & 3318 & 9945 \\
\hline
\end{tabular}

Source: IAB-ReLOC data

international company. Due to the cross-sectional character of the data, in-depth analyses regarding the labour market effects of FDI are not possible. To adequately research this topic, the firm-level dataset was linked to the IAB's establishment-level data (see Schäffler 2014). Only by identifying all establishments belonging to the German MNEs, the employment effects can be analysed in an extensive way. However, the IAB data do not contain a clear firm identifier, only the name of the company the establishment belongs to is provided.

The reason for this is that the IAB data partly come from the social insurance data. To give their social insurance declarations, all German establishments with at least one employee liable for social insurance contributions possess an establishment identifier (see Betriebsnummernservice der Bundesagentur für Arbeit 2018). By assigning the establishment identifiers, the name of the establishment is recorded but no firm identifiers.

Thus, Schäffler (2014) developed a record linkage procedure to link firm-level and establishment-level data of the German firms. Based on the name of the company, the establishments belonging to the same firm are identified. The linked dataset provides longitudinal information on establishment-level as well as firm-level and allows an in-depth analysis of the labour market effects of FDI. What is more important for this paper is the fact that the linked data can be used to conduct a nonresponse analysis as for both the respondents and the non-respondents information on firm characteristics is available. In the Czech Republic, information from the commercial datasets described in Sect. 2.2 is used for conducting the nonresponse analysis.

For each of the four firm groups, Table 2 indicates the number of cases that have been identified, interviewed and linked to the IAB employment data (for Germany) or to commercial databases (for the Czech Republic).

\section{Unit nonresponse analysis}

The IAB-ReLOC data offer a great opportunity to analyse the nonresponse behaviour of firms. Due to the linkage with the IAB employment data comprehensive information is available for respondents and for non-participants.
As the dataset comprises companies of two countries, the question can be addressed if the nonresponse behaviour differs between German and Czech firms. In general, the analysis targets at unit nonresponse, i.e. when a company totally refuses to participate in the survey.

\subsection{Unit nonresponse: definition}

In the literature, two types of unit nonresponse are distinguished (see Janik and Kohaut 2012, for example). ${ }^{6}$ First, unit nonresponse occurs when it is not possible to contact a survey unit. In case of our company survey this noncontact may be due to plant closure, insolvency or firm relocation. Furthermore, the information in the Czech Commercial Register might not have been up to date and/or the company might have initially indicated the wrong or incomplete address. Non-contact due to wrong addresses only occurred in a limited number of cases in Germany; however, in the Czech Republic a higher share of firms could not be contacted due to plant closure (see Table 3). In Germany, around $10 \%$ of the respondents indicated that the firm did not belong to the respective research sample. ${ }^{7}$ In the Czech Republic, this reason for unit nonresponse has only been observed in a limited number of cases. Some companies have not been contacted as the required quota has already been reached. We declare unit nonresponse due to non-contact as neutral nonresponse (see Table 3). Second, unit nonresponse may occur after the contact to the company has been established. Our analysis focuses on this type of unit nonresponse. Non-participation after the contact to the survey unit has been established was due to several reasons. Most often, the interviewers indicated that the target person was not willing to participate in the survey due to time reasons or without indicating any reasons. In a smaller number of cases, the interviewers did not get any information to contact the target person or the target person was not available. In addition, in some cases, the interview was not completed or the reasons for nonresponse were not indicated by the interviewer (see Table 3).

Various reasons can contribute to the occurrence of this type of unit nonresponse. In the literature, a distinction is made between influences that are non-controllable by the researchers and controllable influences (for an overview see Willimack et al. 2002).

Among the non-controllable influences, the company's external environment is to mention. Willimack et al. (2002) have found that general economic conditions

\footnotetext{
${ }^{6}$ Schnell (2012) distinguishes three reasons for unit nonresponse: refusal, illness and non-availability. In firm surveys, illness should play a minor role and is not considered in this study.

${ }^{7}$ For example, firms that were identified as MNEs but were at the time of the survey no longer engaged in FDI in the Czech Republic did not belong to the research sample.
} 
Table 3 Overview of survey results

\begin{tabular}{|c|c|c|c|c|c|}
\hline \multirow[t]{2}{*}{ Response classification } & \multirow[t]{2}{*}{ Survey result } & \multicolumn{2}{|l|}{ Germany } & \multicolumn{2}{|c|}{ Czech Republic } \\
\hline & & German MNEs & German non-MNEs & Czech MNEs & Czech non-MNEs \\
\hline Response & Interview & $\begin{array}{l}368 \\
(15.2 \%)\end{array}$ & $\begin{array}{l}1074 \\
(14.2 \%)\end{array}$ & $\begin{array}{l}445 \\
(13.4 \%)\end{array}$ & $\begin{array}{l}857 \\
(8.6 \%)\end{array}$ \\
\hline \multirow[t]{4}{*}{ Neutral nonresponse } & Firm exists no more & $\begin{array}{l}57 \\
(2.4 \%)\end{array}$ & $\begin{array}{l}93 \\
(1.2 \%)\end{array}$ & $\begin{array}{l}307 \\
(9.3 \%)\end{array}$ & $\begin{array}{l}381 \\
(3.8 \%)\end{array}$ \\
\hline & Wrong address & $\begin{array}{l}82 \\
(3.4 \%)\end{array}$ & $\begin{array}{l}52 \\
(0.7 \%)\end{array}$ & & $\begin{array}{l}36 \\
(0.4 \%)\end{array}$ \\
\hline & Firm does not belong to target group & $\begin{array}{l}329 \\
(13.6 \%)\end{array}$ & $\begin{array}{l}754 \\
(10.0 \%)\end{array}$ & $\begin{array}{l}99 \\
(3.0 \%)\end{array}$ & $\begin{array}{l}71 \\
(0.7 \%)\end{array}$ \\
\hline & Required number of interviews reached & & $\begin{array}{l}1292 \\
(17.1 \%)\end{array}$ & & $\begin{array}{l}2788 \\
(28.0 \%)\end{array}$ \\
\hline \multirow[t]{7}{*}{ Unit nonresponse } & No information on target person provided & $\begin{array}{l}102 \\
(4.2 \%)\end{array}$ & $\begin{array}{l}196 \\
(2.6 \%)\end{array}$ & $\begin{array}{l}84 \\
(2.5 \%)\end{array}$ & $\begin{array}{l}71 \\
(0.7 \%)\end{array}$ \\
\hline & Target person not contactable & $\begin{array}{l}183 \\
(7.6 \%)\end{array}$ & $\begin{array}{l}173 \\
(2.3 \%)\end{array}$ & $\begin{array}{l}11 \\
(0.3 \%)\end{array}$ & $\begin{array}{l}80 \\
(0.8 \%)\end{array}$ \\
\hline & Non-participation due to time reasons & $\begin{array}{l}379 \\
(15.7 \%)\end{array}$ & $\begin{array}{l}1523 \\
(20.1 \%)\end{array}$ & $\begin{array}{l}47 \\
(1.4 \%)\end{array}$ & $\begin{array}{l}555 \\
(5.6 \%)\end{array}$ \\
\hline & Target person refuses participation & $\begin{array}{l}811 \\
(33.5 \%)\end{array}$ & $\begin{array}{l}2396 \\
(31.7 \%)\end{array}$ & $\begin{array}{l}2222 \\
(67.0 \%)\end{array}$ & $\begin{array}{l}4646 \\
(46.7 \%)\end{array}$ \\
\hline & No interview due to other reasons & $\begin{array}{l}108 \\
(4.5 \%)\end{array}$ & $\begin{array}{l}8 \\
(0.1 \%)\end{array}$ & $\begin{array}{l}80 \\
(2.4 \%)\end{array}$ & $\begin{array}{l}439 \\
(4.4 \%)\end{array}$ \\
\hline & Interview not complete & $\begin{array}{l}2 \\
(0.1 \%)\end{array}$ & $\begin{array}{l}5 \\
(0.1 \%)\end{array}$ & $\begin{array}{l}23 \\
(0.7 \%)\end{array}$ & $\begin{array}{l}21 \\
(0.2 \%)\end{array}$ \\
\hline & $\mathrm{N}$ & 2421 & 7566 & 3318 & 9945 \\
\hline
\end{tabular}

Source: IAB-ReLOC data, linked data

may influence survey participation. In weak economic circumstances, companies are more protective and disclose information to outsiders. Another factor is the high number of surveys that especially large companies are obliged to answer. Often, the workload associated with these surveys leads to unit nonresponse in voluntary surveys (Willimack and Nichols 2010). Incontrollable by the researcher is also the kind of data that is kept in business records. Furthermore, researchers usually do not have influence on the respondent selection. For survey participation and data quality, however, it is necessary that the respondent has the authority, the capacity and the motive to respond (Tomaskovic-Devey et al. 1994).

Controllable by the researcher is, in contrast, the survey design comprising sample selection and the choice of the survey mode. There is evidence that the seriousness of the survey increases the willingness to participate (Janik and Kohaut 2012). For household surveys, the relevance of the topic influences survey participation (Groves et al. 2004). For establishment surveys, Willimack et al. (2002) show that data availability is more important for survey participation than the topic.

Janik and Kohaut (2012) stress that not only the survey design but also the interviewer can have a considerable influence on the respondent's willingness to cooperate. In face-to-face surveys, the interviewers have to contact the respondent and gain his cooperation (West and Blom 2017). The first impression the potential respondent gets of the interviewer may facilitate or hinder survey participation. Furthermore, educational level and job experience of the interviewer-both being related to conversation techniques-can influence the participation decision of the respondents.

\subsection{Explanatory variables}

Based on existing literature, we have identified factors that potentially influence the nonresponse probability of firms. As survey design has been the same for all companies, the analysis focuses on the factors that are uncontrollable by the researcher. In both countries, firm and interviewer characteristics ${ }^{8}$ are considered. For the MNEs, in addition, characteristics of the FDI project are analysed. ${ }^{9}$ Data availability is better at the German side than at the Czech side due to the ReLOC linkage procedure (see Sect. 2.4) and due to the fact that the survey institute provided more information on the interviewers

\footnotetext{
${ }^{8}$ Willimack et al. (2002) describe interviewer-related characteristics as controllable by the researcher. In the IAB-ReLOC survey, we provided an interviewer training, but we had no influence on interviewer selection or assignment.

9 Other studies also include respondent-specific variables. Unfortunately, no information on the respondents is available in the IAB-ReLOC data.
} 


$\begin{aligned} & \text { Table } 4 \text { Descriptive statistics } \\
& \text { and the Czech sample }\end{aligned}$
\begin{tabular}{lll}
\hline Variable & $\begin{array}{l}\text { Germany } \\
(\mathrm{N}=7264)\end{array}$ & $\begin{array}{l}\text { Czech Republic } \\
(\mathrm{N}=9162)\end{array}$ \\
& &
\end{tabular}

\begin{tabular}{|c|c|c|}
\hline \multicolumn{3}{|l|}{ Firm characteristics } \\
\hline \multicolumn{3}{|l|}{ No. of employees } \\
\hline $1-5$ & 0.11 & 0.26 \\
\hline $6-9$ & 0.05 & 0.07 \\
\hline $10-19$ & 0.07 & 0.09 \\
\hline $20-49$ & 0.14 & 0.15 \\
\hline $50-99$ & 0.16 & 0.12 \\
\hline 100-199 & 0.15 & 0.07 \\
\hline $200-499$ & 0.23 & 0.06 \\
\hline 500-999 & 0.06 & 0.02 \\
\hline $1000+$ & 0.04 & 0.01 \\
\hline Missing & 0.00 & 0.15 \\
\hline No. of establishments & 3.02 & - \\
\hline MNE group (dummy: yes $=1$ ) & 0.26 & 0.30 \\
\hline $\begin{array}{l}\text { Distance to the German-Czech } \\
\text { border (of the region the firm is } \\
\text { located in, in } \mathrm{km} \text { ) }\end{array}$ & 250.91 & 119.13 \\
\hline Firm in BHP 1975 (dummy: yes =1) & 0.42 & - \\
\hline $\begin{array}{l}\text { Firm age (in years; of firms estab- } \\
\text { lished after 1975) }\end{array}$ & 17.32 & - \\
\hline $\begin{array}{l}\text { Border region (domestic country; } \\
\text { dummy: yes }=1 \text { ) }\end{array}$ & 0.10 & 0.25 \\
\hline \multicolumn{3}{|l|}{ Interviewer characteristics ${ }^{\mathrm{a}}$} \\
\hline Interviewer age (in years) & 60.91 & 43.93 \\
\hline \multicolumn{3}{|l|}{ Education level } \\
\hline Low & 0.55 & - \\
\hline Medium & 0.19 & - \\
\hline High & 0.26 & - \\
\hline No. of assigned firms & 48.00 & 73.59 \\
\hline Male (dummy: yes $=1$ ) & 0.68 & 0.30 \\
\hline
\end{tabular}

FDI characteristics (only for MNE group; N=1895 in Germany, N=2711 in the Czech Republic)

\begin{tabular}{|c|c|c|}
\hline Equity share & 0.92 & 0.90 \\
\hline Direct investment (dummy: yes $=1$ ) & 0.64 & 0.59 \\
\hline $\begin{array}{l}\text { Border region (foreign country; } \\
\text { dummy: yes }=1 \text { ) }\end{array}$ & 0.37 & 0.16 \\
\hline Duration of investment (in years) & 9.98 & 9.82 \\
\hline
\end{tabular}

Source: IAB-ReLOC data. Remarks: In case of categorical variables, the share of the respective category is indicated. In case of metric variables, the mean is indicated. The number of cases is lower than in Table 3 as only cases without any missing values in the explanatory variables are included in the estimations. Table 8 in Appendix shows the distribution according to industry affiliation

a The differences in the descriptive statics for the interviewers between Tables 4 and 5 are due to different numbers of cases. In Table 5 every interviewer is counted only once, whereas in Table 4 the observation level is the firm. Thus, interviewers with a higher number of assigned firms are included more often

for Germany. This allows a more detailed analysis in Germany with a wider range of variables investigated. For the Czech Republic, a subsample of the variables analysed in Germany is examined. Table 4 gives an overview of the explanatory variables included in the nonresponse analysis.

\subsubsection{Firm specific characteristics}

With regards to firm-specific characteristics, previous studies have shown that firm size influences the nonresponse probability (for an overview see Petroni et al. 2004). With rising firm size, the number of mandatory surveys a firm has to answer increases what in return has negative consequences for the probability to participate in an additional (voluntary) survey (Willimack and Nichols 2010). Furthermore, with rising firm size the organisational structures become more complex. For large firms, the provision of the required information may be more complicated than for small or medium-sized companies (Tomaskovic-Devey et al. 1994). In addition, TomaskovicDevey et al. (1994) state that the individual identification with the firm decreases with rising firm size what influences the personal motivation of the respondent to participate in the survey and may cause unit nonresponse. Thus, the nonresponse probability should increase with rising firm size. We measure firm size as the total number of employees in 2010. The variable is included in classified form in our analysis. ${ }^{10}$ Moreover, the organisational structure of a firm becomes more complex with a rising number of establishments belonging to the firm. As a consequence, the nonresponse probability should rise with the number of establishments belonging to the firm, as has been found, for instance, by Phipps and Jones (2007). There is evidence that personal involvement in the survey's topic reduces unit nonresponse in household surveys (Groves et al. 2004) as well as in organisation studies (Willimack et al. 2002). We expect that MNEs and firms located closer to the German-Czech border are more interested in the topic and show a higher participation rate. To account for this, we include the information if the company belongs to the MNE group and the firm's distance to the neighbouring country. ${ }^{11}$ Furthermore, we control for the age of the firm and for industry affiliation (in 18 classes). In the Czech Republic, due to data restrictions, only a smaller set of variables is analysed, comprising firm size, MNE group affiliation, distance to Germany and industry affiliation.

\footnotetext{
${ }^{10}$ While in Germany, we know the exact number of employees, this information is only available to us in classified form in the Czech Republic. To establish comparability, we measure firm size in classes in both countries. The following classes are distinguished: 1-5, 6-9, 10-19, 20-49, 50-99 (reference category), 100-199, 200-499, 500-999, and 1000 and more employees.

11 This distance refers to the linear distance (measured in $\mathrm{km}$ ) of the region the firm is located in (in Germany: spatial planning region, in the Czech Republic: district) to the German-Czech border.
} 


\subsubsection{Interviewer characteristics}

Previous studies have shown that interviewers may influence survey participation (see Groves et al. 2009; Pickery and Loosveldt 2002). Especially experience in conducting interviews and a good knowledge of conversation techniques have been found to positively influence the recruiting ability (Campanelli and O'Muircheartaigh 1999; Groves et al. 2009; West and Blom 2017). To account for experience, Janik and Kohaut (2012), for example, refer to the number of years the interviewers have already been working for the specific survey institute. Unfortunately, this information is not available in our data. Thus, we include the number of firms assigned to an interviewer within the IAB-ReLOC survey to account for the involvement of the interviewer in the survey. A high number of assigned firms could also reflect that working as an interviewer is a person's main job. As these professional interviewers should do a better job in recruiting respondents we expect a positive sign of this variable. As there is evidence that interviewer age influences survey participation (West and Blom 2017), we include this variable. We suppose that the interviewer's job experience rises with increasing age what leads to a better understanding of recruiting respondents and thus to a lower nonresponse probability. However, we expect a non-linear relationship as Josten and Trappmann (2016) have found that the response quality decreases with interviewer age. Thus, we also include interviewer age squared. ${ }^{12}$ Moreover, we account for the educational level of the interviewers. We differentiate between low, medium and high education and expect that the nonresponse probability shrinks with rising educational level as education is linked to conversation skills. In the Czech Republic, information on the educational level of the interviewer is not available. Furthermore, we control in both countries for interviewer gender. However, previous studies have only found weak or no relationship between interviewer gender and recruiting success (for an overview see West and Blom 2017).

Table 5 gives an overview of descriptive statistics describing the interviewers that conducted the IAB-ReLOC survey. In general, more interviewers have been involved in Germany (566 vs. 246 in the Czech Republic), probably due to the larger country size. In both countries, most interviewer were involved in interviewing firms from both the MNE and the reference group. The average age of the interviewers is clearly higher in Germany (60 years) than in the Czech Republic (45 years). This difference might result in a higher experience of the German interviewers.

\footnotetext{
${ }^{12}$ This variable does not appear in the estimation results (see Table 6 and Table 7) as we report the average marginal effects (AMEs). These cannot be computed for interaction terms but only for the component terms, i.e. the variables included in the interaction term (Williams 2012). The estimated coefficients are reported in Tables 9 and 10 in Appendix.
}

Furthermore, while in Germany approximately two-thirds of the interviewers are male, in the Czech Republic this share is only one-third. This difference should not matter as previous studies have shown that interviewer gender does not influence survey participation. More important for recruiting respondents is the involvement of the interviewers in the survey as displayed by the number of interviews and contacts. On average, these two indicators are higher in the Czech Republic what reflects the lower number of interviewers. In Germany, $52 \%$ of the interviewers have a low education level, $19 \%$ have a medium and $28 \%$ have a high education level. ${ }^{13}$

\subsubsection{Characteristics of the FDI project}

We suppose that the characteristics of the FDI project influence the response behaviour of the MNEs as, inter alia, the interest in the survey topic and the permission to participate may be related to these characteristics.

A variable characterising the strength of the relationship between the German firm and the Czech affiliate is the equity share the German MNE holds in the Czech company. We expect the influence on nonresponse of this variable to vary between the two countries: For German MNEs, we presume that the nonresponse probability shrinks with rising equity share due to increasing decision power and better availability of information on the FDI project. For Czech MNEs, in contrast, we assume that the nonresponse probability increases with rising equity share of the German parent company due to smaller decision power and higher dependence. The same relation is expected for FDI projects that are direct investments $^{14}$ due to a higher decision power of the German MNE. We also expect that the nonresponse probability is positively correlated to the duration of the investment (measured in years since the German investor entered the Czech firm) due to a higher awareness of the company part at the other side of the border and-related to that-better data availability on the FDI relationship. In

\footnotetext{
${ }^{13}$ In the German data, information on the highest achieved school leaving certificate of each interviewer is available. According to this information, the education level is categorised as follows: Low education level refers to persons with elementary school leaving certificate and to persons that have visited a secondary school but do not (yet) possess a school leaving certificate. Medium education comprises persons with university-entrance diploma ("Abitur") and persons that have visited a high school/university but have not graduated (yet). High education refers to person with a high school/university degree.

14 The IAB-ReLOC data build on Czech firms with a direct German owner. However, there are German private persons and holding companies among the owners. For the private persons, it has been verified if they own a German company. If such a firm could be identified, this so called sister company was included in the German MNE group. Holding companies have, if possible, been replaced by the main company of the associate group. The FDI projects in which German firms replacing private persons or holding companies are involved are referred to as indirect investments.
} 
Table 5 Descriptive statistics on the interviewers

\begin{tabular}{lll}
\hline & Germany & Czech Republic \\
\hline Age (in years) & 60.23 & 44.54 \\
Male & 0.64 & 0.32 \\
Average number of interviews & 3.08 (min: 0, max: 184) & 5.41 (min: 0, max: 41) \\
Average number of assigned firms & 22.33 (min: 1, max: 261) & 46.66 (min: 1, max: 196) \\
Education level & & - \\
Low & 0.52 & - \\
Medium & 0.19 & - \\
High & 0.28 & 246 \\
\hline
\end{tabular}

Source: IAB-ReLOC data. Remarks: In case of categorical variables, the share of the respective category is indicated. In case of metric variables, the mean is indicated

addition, we include in the analysis the information if the company part at the other side of the border is located in the border region. In Germany, the border region consists of the spatial planning regions that share a common border with the Czech Republic and in the Czech Republic of the NUTS3 regions adjacent to Germany. ${ }^{15}$

\subsection{Estimation method}

To analyse what factors contribute to unit nonresponse, a logistic random-intercept model is estimated (Josten and Trappmann 2016; Rabe-Hesketh and Skrondal 2008) as it is possible that the error terms are correlated across the observations interviewed by the same interviewer.

In a first step, we estimate the empty model to obtain the intraclass correlation coefficient (ICC) and get an impression for the importance of the interviewer effects.

$$
\operatorname{logit}\left\{\operatorname{Pr}\left(y_{i j}=1 \mid x_{i j}, z_{j}, \zeta_{j}\right)\right\}=\beta_{1}+\zeta_{j}
$$

The dependent variable $y$ takes the value of 1 if a specific company $i$ refuses to participate in the survey and 0 otherwise. The empty model only includes a mean intercept $\beta_{1}$ and a random intercept $\zeta_{j}$ that expresses the deviation of interviewer $j$ 's intercept from $\beta_{1}$. Based on the estimation results of the empty model, we estimate the ICC that reflects the variance share that is generated by the interviewers (for the calculation of the ICC see Snijders and Bosker 2012, for example). A high ICC can arise

\footnotetext{
${ }^{15}$ In cases, where a German parent company is engaged in more than one Czech firm, the variables containing information on the FDI project refer to the affiliate in which the German firm owns the largest share. In cases where two or more Czech affiliates have the same share, the affiliate with the longer FDI duration is selected. If not only the share but also the duration is the same, a random selection is made. The same holds for the Czech sample: In cases where Czech affiliates have more than one German parent company, the FDI features refer to the parent company with the highest equity share. In cases where two or more German firms hold the same share, the parent company with the longer FDI duration is selected. If not only the share but also the duration is the same, a random selection is made.
}

when answers from respondents interviewed by the same interviewer are more similar to each other than answers from other respondents (West and Olson 2010). In our study, a high ICC implies that potential respondents are more similar in their decision to participate in the survey when they are recruited by the same interviewer.

In a second step, we augment the empty model by variables referring to the firm-level $\left(X_{i j}\right)$ and variables characterising the interviewers $\left(Z_{j}\right)$.

$$
\begin{aligned}
& \operatorname{logit}\left\{\operatorname{Pr}\left(y_{i j}=1 \mid x_{i j}, z_{j}, \zeta_{j}\right)\right\}=\beta_{1}+\beta_{2} x_{i j 2} \\
& \quad+\cdots+\beta_{k} x_{i j k}+\beta_{k+1} z_{j l}+\cdots+\beta_{k+l} z_{j l}+\zeta_{j}
\end{aligned}
$$

As data availability differs for the two countries, the estimations are run separately for each country. To reveal differences in the response behaviour between German and Czech firms we in addition estimated a model including firms from both countries. In that model, the set of variables is restricted to the variables available for the Czech side. For all estimations, the melogit command in stata has been used.

\subsection{Estimation results}

The estimation results for the German sample are presented in Table 6 and the results for the Czech sample in Table 7. For both countries, three different models are estimated. The first model examines only firm characteristics (column 1 of Tables 6,7 ), the second model includes in addition interviewer characteristics (column 2 of Tables 6, 7) and the third model comprises firm and interviewer characteristics as well as information on the characteristics of the FDI projects (see column 3 of Tables 6, 7). In all tables, the average marginal effects (AMEs) are indicated. ${ }^{16}$

\footnotetext{
16 The estimated coefficients are reported in Appendix in Tables 9, 10. The results of the estimation including German and Czech firms are reported in Table 11.
} 
Table 6 Nonresponse analysis: results of multi-level logit models (nonresponse $=1$ ) for German firms

\begin{tabular}{|c|c|c|c|}
\hline & $\begin{array}{l}1 \\
\text { AME }\end{array}$ & $\begin{array}{l}2 \\
\text { AME }\end{array}$ & $\begin{array}{l}3 \\
\text { AME }\end{array}$ \\
\hline \multicolumn{4}{|l|}{ Firm characteristics } \\
\hline \multicolumn{4}{|l|}{ No. of employees 2010 (ref.: 50-99): } \\
\hline $1-5$ & $-0.0679^{* * *}$ & $-0.0704^{* * *}$ & $-0.0750^{* * *}$ \\
\hline $6-9$ & $-0.0608^{* *}$ & $-0.0629^{* *}$ & $-0.0662^{* * *}$ \\
\hline $10-19$ & $-0.0370^{*}$ & $-0.0392^{*}$ & $-0.0404^{*}$ \\
\hline $20-49$ & -0.0207 & -0.0224 & -0.0238 \\
\hline $100-199$ & 0.0133 & 0.0136 & 0.0131 \\
\hline 200-499 & $0.0294^{* *}$ & $0.0309^{* *}$ & $0.0294^{* *}$ \\
\hline $500-999$ & $0.0382^{*}$ & $0.0399^{*}$ & $0.0390^{*}$ \\
\hline $1000+$ & 0.0375 & 0.0404 & 0.0424 \\
\hline Firm in BHP 1975 (yes=1) & 0.0221 & 0.0243 & 0.0387 \\
\hline Firm age (in years, In) & 0.0078 & 0.0080 & 0.0126 \\
\hline No. of establishments (In) & 0.0069 & 0.0072 & 0.0076 \\
\hline MNE group (yes $=1$ ) & 0.0124 & 0.0163 & $0.1237^{* * *}$ \\
\hline Distance to Czech border (in km, In) & $0.0324^{* *}$ & $0.0382^{* *}$ & $0.0387^{* *}$ \\
\hline Border region Germany (yes $=1$ ) & 0.0213 & 0.0297 & 0.0317 \\
\hline \multicolumn{4}{|l|}{ Interviewer characteristics } \\
\hline Male $($ yes $=1)$ & & -0.0013 & -0.0009 \\
\hline Interviewer age (in years) & & $-0.0032^{* * *}$ & $-0.0032^{* * *}$ \\
\hline \multicolumn{4}{|l|}{ Education level (ref:: high) } \\
\hline Low & & 0.0216 & 0.0220 \\
\hline Medium & & $0.0668^{* * *}$ & $0.0666^{* * *}$ \\
\hline No. of assigned firms & & $-0.0008^{* * *}$ & $-0.0008^{* * *}$ \\
\hline \multicolumn{4}{|l|}{ FDI characteristics } \\
\hline Equity share (In) & & & -0.0059 \\
\hline Direct investment (yes $=1$ ) & & & $-0.0700^{* * *}$ \\
\hline Duration of investment (in years, In) & & & $-0.0350^{* * *}$ \\
\hline Border region Czech Republic (yes $=1$ ) & & & -0.0277 \\
\hline Random part: intercept variance $\left(\zeta_{j}\right)$ & $1.2088^{* * *}$ & $1.0630^{* * *}$ & $1.0760^{* * *}$ \\
\hline ICC & 0.2687 & 0.2442 & 0.2465 \\
\hline No. of observations & 7264 & 7264 & 7264 \\
\hline Log likelihood & -3143.4866 & -3125.9509 & -3115.4869 \\
\hline
\end{tabular}

$A M E$ average marginal effect

Significance level: ${ }^{*}<0.1,{ }^{* *}<0.05,{ }^{* * *}<0.01$. Control variables for industry affiliation included. The explanatory variables referring to FDI features are modelled as interactions by assigning them the value of 0 in case of non-MNEs

With regards to interviewer effects, we obtain quite high values for the ICC in the empty model. Thus, in all four subsamples substantial interviewer effects with respect to the recruitment success can be observed. The ICC takes the value 0.2831 in the German sample and 0.4263 in the Czech sample. Especially the value in the Czech sample is quite high compared to previous research. Based on a CAPI study, West et al. (2013), for instance, obtain an ICC of 0.11 for binary response indicators. However, previous research has also revealed high interviewer effects: When analysing network size questions, Brüderl et al. (2013) obtain ICC values of around
0.40 and Josten and Trappmann (2016) of around 0.30 . With respect to the Czech Republic, there is only little evidence on ICC values, especially what concerns studies focusing on unit nonresponse. However, according to Beullens and Loosveldt (2016), the Czech Republic ranges among the countries with the highest ICC values in the European Social Survey (ESS): Based on an analysis of 48 survey items, the average ICC in the Czech Republic exceeds 0.25 in some years. In their analysis on interview length in the ESS, Loosveldt and Beullens (2013) identify an ICC of 0.15 for the Czech Republic. In our study, the values of the ICC are reduced when including 
Table 7 Nonresponse analysis: results of multi-level logit model (nonresponse $=1$ ) for Czech firms

\begin{tabular}{|c|c|c|c|}
\hline & 1 & 2 & 3 \\
\hline & AME & AME & AME \\
\hline \multicolumn{4}{|l|}{ Firm characteristics } \\
\hline \multicolumn{4}{|l|}{ No. of employees 2010 (ref.: 50-99) } \\
\hline $1-5$ & $0.0567^{* * *}$ & $0.0537^{* * *}$ & $0.0508^{* * *}$ \\
\hline $6-9$ & 0.0159 & 0.0155 & 0.0135 \\
\hline $10-19$ & 0.0180 & 0.0180 & 0.0181 \\
\hline $20-49$ & 0.0131 & 0.0128 & 0.0125 \\
\hline $100-199$ & $0.0404^{* *}$ & $0.0385^{* *}$ & $0.0387^{* *}$ \\
\hline 200-499 & $0.0688^{* * *}$ & $0.0646^{* * *}$ & $0.0650^{* * *}$ \\
\hline $500-999$ & $0.0630^{* *}$ & $0.0594^{* *}$ & $0.0592^{* *}$ \\
\hline $1000+$ & $0.1287^{* * *}$ & $0.1205^{* * *}$ & $0.1198^{* * *}$ \\
\hline Unknown & $0.1172^{* * *}$ & $0.1099 * * *$ & $0.1065^{* * *}$ \\
\hline MNE group (yes $=1$ ) & $-0.0530^{* * *}$ & $-0.0507^{* * *}$ & 0.0094 \\
\hline Distance to German border (in km, In) & $-0.0297^{* *}$ & $-0.0259^{* *}$ & $-0.0249^{* *}$ \\
\hline Border region Czech Republic (yes $=1$ ) & $-0.0859^{* * *}$ & $-0.0721^{* *}$ & $-0.0720^{* *}$ \\
\hline \multicolumn{4}{|l|}{ Interviewer characteristics } \\
\hline Male $($ yes $=1)$ & & 0.0022 & 0.0020 \\
\hline Interviewer age (in years) & & $-0.0046^{* * *}$ & $-0.0046^{* * *}$ \\
\hline No. of assigned firms & & 0.0004 & $0.0004^{*}$ \\
\hline \multicolumn{4}{|l|}{ FDI characteristics } \\
\hline Equity share (In) & & & $0.0321^{*}$ \\
\hline Direct investment (yes $=1$ ) & & & $-0.0307^{* *}$ \\
\hline Duration of investment (in years, In) & & & $-0.0167^{* *}$ \\
\hline Border region Germany (yes $=1$ ) & & & 0.0073 \\
\hline Random part: intercept variance $\left(\zeta_{j}\right)$ & $2.2828^{* * *}$ & $1.8653^{* * *}$ & $1.8684^{* * *}$ \\
\hline ICC & 0.4096 & 0.3618 & 0.3622 \\
\hline No. of observations & 9162 & 9162 & 9162 \\
\hline Loglikelihood & -2999.3667 & -2980.0121 & -2973.5426 \\
\hline
\end{tabular}

AME average marginal effect

Significance level: ${ }^{*}<0.1,{ }^{* *}<0.05,{ }^{* * *}<0.01$. Control variables for industry affiliation included. The explanatory variables referring to FDI features are modelled as interactions by assigning them the value of 0 in case of non-MNEs

further explanatory variables. Especially the inclusion of interviewer characteristics contributes to a reduction of the ICC. ${ }^{17}$

The estimation results for the German sample (see Table 6) show that firm as well as interviewer characteristics influence the nonresponse behaviour. The estimation specification analysing firm and interviewer characteristics (see column 2 of Table 6) reveals that larger firms have a higher probability for nonresponse than smaller firms. Compared to companies with 50 to 99 employees, firms with one to 19 employees have a significantly lower nonresponse probability and firms with 200 to 999 employees

\footnotetext{
17 To assess the effects of the interviewers, we have analysed how much the ICC changes when excluding successively every interviewer from the estimation (for details on this procedure see Brüderl et al. 2013, for example). In Germany, the exclusion of some specific interviewers clearly reduces the ICC (the smallest value is 0.2697 compared to 0.2831 in the empty model). In the Czech Republic, this phenomenon is not observed.
}

have a significantly higher nonresponse probability. The AMEs for the other size categories are not significant. This outcome is in line with our hypothesis and confirms the result of Janik and Kohaut (2012) that in small firms the respondents are more likely to have the authority, the capacity and the motivation to answer the questionnaire. With respect to our hypothesis that companies that are more interested in the survey topic have a higher participation probability, our results are ambiguous: On the one hand, firms located farther away from the GermanCzech border have a higher nonresponse probability. As can be seen from the value of the AME the nonresponse probability increases on average by 3.8 percentage points when the distance to the Czech border increases by $1 \%$. On the other hand, the border region dummy is insignificant what indicates that when controlling for the distance to the border, there is no additional border region effect. Furthermore, the companies belonging to the German 
MNE group do not show a higher participation rate. This confirms previous research that has shown that survey topic is of rather little importance in business surveys (Willimack et al. 2002). The number of establishments that belong to a firm does not influence survey participation. Thus, the size measured in number of employees is more relevant to the response decision than the size measured in number of establishments. In addition, we find that the nonresponse probability varies between industries. ${ }^{18}$ Regarding the interviewer effects, the nonresponse probability decreases with rising interviewer age. When interviewer age increases by one year, the nonresponse probability decreases on average by 0.3 percentage points what confirms our assumption that older interviewers are more successful in recruiting respondents. In addition, the nonresponse probability decreases when the number of firms assigned to an interviewer increases. This shows that interviewers that are more involved in the survey are more successful in recruiting respondents. Finally, the results show that interviewers with a medium education level have a significantly higher probability to generate nonresponse than interviewers with a high education level. For interviewers with a low education level, the AME is also positive but not significant. Throughout all estimations, the gender of the interviewer has no influence on nonresponse what confirms previous results (West and Blom 2017). Column 3 of Table 6 shows the estimation results when in addition the characteristics of the FDI project ${ }^{19}$ are analysed. For the MNEs, the involvement in the survey topic seems to influence the decision to participate in the survey. Firms with a direct investment in the Czech Republic have a lower nonresponse probability than firms that are indirectly linked to a Czech company. In addition, the duration of the investment has a significantly negative sign too: When FDI duration rises by $1 \%$, the probability for unit nonresponse decreases by 3.5 percentage points. Firms with a longer investment experience in the Czech Republic might not only have a more intense relationship to their Czech affiliate but also face a better data availability. With respect to the equity share of the German parent company our hypothesis is not confirmed. The AME of this variable shows the expected sign but is not statistically significant. If the Czech affiliate is located in the border region or not has no significant effect on the nonresponse probability of the German parent company.

Turning to the results for the Czech sample (see column 2 of Table 7), the assumption that the nonresponse

\footnotetext{
18 The results for the industry dummies are available from the authors upon request.

19 As characteristics of the FDI project are per definition only available for the MNEs, the explanatory variables referring to FDI features are modelled as interactions by assigning them the value of 0 in case of non-MNEs.
}

probability increases with firm size is mostly confirmed, too. While the firms with a size between one and five employees have a significantly higher nonresponse probability than companies with 50 to 99 employees, the nonresponse probability for the size classes from six to 49 employees is not significantly different from that of firms with 50 to 99 employees. Companies with more than 99 employees show a significantly higher nonresponse probability than the reference category. This confirms our assumption that larger firms have a higher nonresponse probability due to a higher coordination effort. Not in line with our assumption is the result for the companies with one to five employees. However, in these very small companies there might be no account staff but the owner has to fulfil these tasks and has no time for survey participation. That a lack of staff dedicated to information processing can be a source for nonresponse has also been found by previous research (Thompson and Washington 2013; Tomaskovic-Devey et al. 1994). The variable reflecting the affiliation to the MNE group shows a significantly negative AME. Firms with a German owner on average have a 5.1 percentage points lower nonresponse probability than domestic firms. In contrast to the result for the German sample, this outcome is in line with our hypothesis that the MNEs are more interested in the survey topic and show a higher participation rate. What concerns our assumption that firms located near Germany have a higher participation rate, the result is ambiguous: While the dummy variable displaying if the firm is located in the border region shows a significantly negative AME, what confirms our hypothesis, the AME for the firm's distance to Germany is significantly negative what contradicts our expectations. Our interpretation for this result is that firms located in the border region are more interested in the survey topic than firms located in non-border regions. For firms that are not located in the border region, however, a smaller distance to Germany does not result in a higher interest and thus a higher participation rate. The differences in the nonresponse behaviour between industries are not pronounced. ${ }^{20}$ With regards to interviewer characteristics, older interviewers are more successful in recruiting respondents. This result is stable throughout all estimations - independent of the country of origin and the international integration of the companies. In the estimation model in column 2 of Table 7 the number of firms that is assigned to an interviewer is not correlated to the nonresponse probability. In the full model in column 3 of Table 7, the number of assigned firms has a significantly positive AME. Thus, when the number of assigned firms rises, the nonresponse probability slightly increases. As in Germany, the characteristics of the FDI project

\footnotetext{
${ }^{20}$ The results for the industry dummies are available from the authors upon request.
} 
influence survey participation. That the probability for unit nonresponse increases with a higher equity share of the German owner corresponds to our assumption that decision power influences survey participation. Czech affiliates with a more dominant German owner might possess lower decision power and thus not dare to participate in the survey. That Czech affiliates that are directly linked to a German firm have a lower nonresponse probability confirms our hypotheses that these firms are, first, more interested in the survey topic and are, second, better informed about the company relation. The results that the nonresponse probability decreases when the duration of the investment increases can be interpreted in the same direction: Firms that have for a longer period of time been owned by a German investor should be better informed about this company relation. The location of the German company with respect to the border region does not influence the participation decision.

By comparing the estimation results obtained in the separate estimations for the two countries, there seem to be some differences in the factors influencing the participation behaviour between German and Czech firms. First, in Germany, interviewers that are more involved in the survey have a higher recruitment success while in the Czech Republic the nonresponse probability slightly increases when the number of firms assigned to one interviewer rises. Second, the influence of the distance variable differs between the two countries. In Germany, firms that are located closer to the Czech Republic show a lower probability for nonresponse, while in the Czech Republic the nonresponse probability decreases with rising distance to Germany. In the Czech Republic, however, firms that are located in the border region show a lower nonresponse probability than firms located in non-border regions. For Germany, no such effect is observed. Furthermore, in the estimations displayed in columns 1 and 2 of Table 6 and Table 7 differences concerning the affiliation to the MNE group can be observed: In the Czech Republic, the MNEs show the expected lower nonresponse probability while in Germany there is no significant difference between MNEs and non-MNEs. Third, when including FDI characteristics in the model, one further difference evolves. While the equity share of the German parent company is not significantly correlated to unit nonresponse in Germany, Czech affiliates with a higher German equity share show a higher nonresponse probability. This might be a sign for lower decision power and/or worse data availability in the Czech firm when the German parent company is more involved. The finding supports the hypothesis of Tomaskovic-Devey et al. (1994) that survey nonresponse is higher when the decision maker is geographically removed from the interviewed firm unit. In both countries, the nonresponse probability is lower for direct FDI relations as well as for FDI relations with a longer duration and the participation rate is higher among the small and medium-sized companies than among the large companies.

Most of the differences and commonalities observed by comparing the separate estimations for the two countries are confirmed when estimating a model that includes observations from both countries (see Appendix Table 11). The estimated coefficient for the interaction term between Czech firm and MNE group has a negative sign in all model specifications confirming that firms in the Czech MNE group show a lower nonresponse rate than in the German MNE group. The difference in the relation between nonresponse probability and distance to the border is confirmed by the significantly negative coefficient of the interaction term between Czech firm and distance to the border. The same holds for the difference in the border region. The significantly positive coefficient of the interaction term between Czech firm and number of assigned interviews confirms a further difference between the two countries. That in the Czech Republic the nonresponse probability rises with a higher equity share of the German owner is, however, not confirmed in the estimation results of Appendix Table 11.

As robustness checks, the estimations have been run for samples that have been restricted according to interviewer characteristics. All estimations have been run for samples containing, first, only interviewers with more than five contacts, second, only interviewers with at least one interview, third, only interviewers with at least two interviews and, last, only interviewers with less than 50 interviews for the German sample and interviewers with less than 40 interviews for the Czech sample. Furthermore, the estimations for the German sample has been run with the same set of variables that is available for the Czech side. For all robustness checks, the results remain stable. ${ }^{21}$

\section{Conclusion}

The labour market effects of FDI are a topic of constant interest. However, research possibilities are limited as most of the datasets applied in empirical research on FDI suffer from selectivity and contain only firms and/or FDI projects above a certain size threshold. To overcome these shortcomings, the IAB has created a unique dataset that will allow an in-depth analysis of the labour market effects of German FDI in the Czech Republic, the IAB-ReLOC data.

The contribution of this paper is twofold: First, it gives an overview of the IAB-ReLOC data. By presenting the

\footnotetext{
${ }^{21}$ The results of the robustness checks are available from the authors upon request.
} 
data generation process, guidance for similar data compilation projects is provided. The second and main focus of the paper is on the analysis of unit nonresponse in the IAB-ReLOC survey. As administrative data and information on the interviewer is available for the responding and for the nonresponding units, an in-depth analysis of the factors influencing the participation decision can be carried out. Due to missing information on the nonrespondents in most firm-level datasets, previous empirical evidence in this field of research is rare. In addition, new insights into the survey participation decision of firms in a cross-border context are revealed.

The estimation of multi-level logit models shows that the probability for unit nonresponse is influenced by firm characteristics, interviewer features and by characteristics of the FDI project. In Germany as well as in the Czech Republic, larger firms have a higher probability to refuse survey participation and interviewers that are more involved in the survey as measured in terms of assigned firms are more successful in recruiting respondents. Some differences in the survey participation between German and Czech firms emerge. The first pronounced difference is related to the location of the firms. In Germany, the nonresponse probability rises with the distance between the location of the company and the Czech Republic-indicating that for firms located closer to the border the survey topic is more interesting. In the Czech Republic, however, the opposite is true: With exception of the firms located in the border region to Germany, the nonresponse probability decreases when a firm's distance to Germany rises. The second important finding is related to FDI features. Both the German parent companies and their Czech affiliates show a lower nonresponse probability when they are involved in a direct foreign investment compared to indirect investment forms what indicates a tighter interconnectedness of the firms. In the Czech MNE group, however, the nonresponse probability rises with the equity share the German company owns. This suggests that the decision power of a firm relates to the participation decision.

The fact that this paper has shown that unit nonresponse is not random in the dataset is not a hurdle for future research based on the IAB-ReLOC dataset. Due to the sophisticated record linkage, company level information on labour market characteristics is available for the total sample of German parent companies and can be exploited to get in-depth insights into the labour market effects of FDI comprising, for example, employment and wage effects. In addition, the IAB-ReLOC dataset offers also great opportunities for further methodological analyses. For instance, the question comes up if the observed unit nonresponse pattern also results in a nonresponse bias.
Abbreviations

AME: average marginal effects; CEEC: Central and Eastern European Countries; CERGE-El: Center for Economic Research and Graduate Education-Economics Institute; CORIS: Cluster-Oriented Regional Information System; FDI: foreign direct investment; IAB: Institute for Employment Research (Institut für Arbeitsmarkt- und Berufsforschung); ICC: intraclass correlation coefficient; ReLOC: Research on Locational and Organisational Change; MNE: multinational enterprise.

\section{Authors' contributions \\ Every author contributed-more or less - to all sections of the paper. NL was mainly involved in the description of the data generation process. JS was in the first place responsible for linking the identified German-Czech companies to IAB's employment statistics and has primarily prepared the data for this paper. The empirical strategy was mainly developed by VH. She was also in charge of running the estimations and interpreting the results. All authors read and approved the final manuscript.}

\section{Acknowledgements}

The authors thank Lutz Bellmann, Uwe Blien, Frauke Kreuter, Hans Ludsteck, Joachim Möller, Michael Moritz and Katja Wolf for helpful remarks and suggestions.

\section{Competing interests}

The authors declare that they have no competing interests.

\section{Availability of data and materials}

The data that support the findings of this study are available from the Institute for Employment Research (IAB) but restrictions apply to the public availability of these data, which were used under license for the current study. Data are however available from the authors upon reasonable request and with permission of $I A B$ and can only be accessed at IAB.

\section{Appendix}

See Tables 8, 9, 10, 11.

Table 8 Industry affiliation of German and Czech firms (shares of firms belonging to each category)

\begin{tabular}{lll}
\hline Industry affiliation (18 classes) & German sample & Czech sample \\
\hline Agriculture, forestry, fishing & 0.009 & 0.017 \\
Mining and quarrying & 0.023 & 0.019 \\
Food and beverages & 0.048 & 0.030 \\
Consumer goods & 0.052 & 0.054 \\
Producer goods & 0.083 & 0.062 \\
Investment goods & 0.231 & 0.196 \\
Construction & 0.049 & 0.033 \\
Wholesale and retail trade & 0.193 & 0.298 \\
Transportation and storage & 0.051 & 0.041 \\
Information and communication & 0.033 & 0.035 \\
Accommodation & 0.004 & 0.005 \\
Financial and insurance services & 0.032 & 0.006 \\
Economic, scientific and professional & 0.165 & 0.184 \\
services & & 0.0004 \\
Education & 0.003 & 0.009 \\
Health and social care & 0.009 & 0.008 \\
Other services & 0.009 & 0.000 \\
Non-profit organisations & 0.003 & 0.000 \\
Public administration & 7264 & \\
N & & 0.005 \\
\hline
\end{tabular}


Table 9 Nonresponse analysis: results of multi-level logit model (nonresponse $=1$ ) for German firms-estimated coefficients

\begin{tabular}{|c|c|c|c|}
\hline & 1 & 2 & 3 \\
\hline & Coefficients & Coefficients & Coefficients \\
\hline \multicolumn{4}{|l|}{ Firm characteristics } \\
\hline \multicolumn{4}{|l|}{ No. of employees 2010 (ref.: 50-99): } \\
\hline $1-5$ & $-0.5069^{* * *}$ & $-0.5003^{* * *}$ & $-0.5337^{* * *}$ \\
\hline $6-9$ & $-0.4588^{* * *}$ & $-0.4509^{* * *}$ & $-0.4768^{* * *}$ \\
\hline $10-19$ & $-0.2903^{*}$ & $-0.2907^{*}$ & $-0.3018^{* *}$ \\
\hline $20-49$ & -0.1673 & -0.1708 & -0.1828 \\
\hline 100-199 & 0.1151 & 0.1106 & 0.1074 \\
\hline $200-499$ & $0.2656^{* *}$ & $0.2608^{* *}$ & $0.2496^{* *}$ \\
\hline 500-999 & $0.3524^{*}$ & $0.3439^{*}$ & $0.3389^{*}$ \\
\hline $1000+$ & 0.3460 & 0.3487 & 0.3715 \\
\hline Firm in BHP 1975 (yes=1) & 0.1872 & 0.1935 & 0.3114 \\
\hline Firm age (in years, In) & 0.0653 & 0.0635 & 0.1003 \\
\hline No. of establishments (In) & 0.0576 & 0.0572 & 0.0603 \\
\hline MNE group (yes $=1$ ) & 0.1055 & 0.1311 & $1.1194^{* * *}$ \\
\hline Distance to Czech border (in km, In) & $0.2719^{* *}$ & $0.3019^{* *}$ & $0.3073^{* *}$ \\
\hline Border region Germany (yes $=1$ ) & 0.1853 & 0.2458 & 0.2650 \\
\hline \multicolumn{4}{|l|}{ Interviewer characteristics } \\
\hline Male $($ yes $=1)$ & & -0.0103 & -0.0073 \\
\hline Interviewer age (in years) & & $0.0900^{* *}$ & $0.0871^{* *}$ \\
\hline Interviewer age (in years) squared & & $-0.0009^{* * *}$ & $-0.0009^{* * *}$ \\
\hline \multicolumn{4}{|l|}{ Education level (ref.: high) } \\
\hline Low & & 0.1626 & 0.1663 \\
\hline Medium & & $0.5490^{* * *}$ & $0.5496^{* * *}$ \\
\hline No. of assigned firms & & $-0.0067^{* * *}$ & $-0.0066^{* * *}$ \\
\hline \multicolumn{4}{|l|}{ FDI characteristics } \\
\hline Equity share (In) & & & -0.0465 \\
\hline Direct investment (yes $=1$ ) & & & $-0.5164^{* * *}$ \\
\hline Duration of investment (in years, In) & & & $-0.2783^{* * *}$ \\
\hline Border region Czech Republic (yes $=1$ ) & & & -0.2117 \\
\hline Const. & -0.5136 & $-2.6392^{* *}$ & $-2.6957^{* *}$ \\
\hline Random part: intercept variance $\left(\zeta_{i}\right)$ & $1.2088^{* * *}$ & $1.0630^{* * *}$ & $1.0760^{* * *}$ \\
\hline ICC & 0.2687 & 0.2442 & 0.2465 \\
\hline No. of observations & 7264 & 7264 & 7264 \\
\hline Log likelihood & -3143.4866 & -3125.9509 & -3115.4869 \\
\hline
\end{tabular}

Significance level: ${ }^{*}<0.1, * *<0.05, * * * 0.01$. Control variables for industry affiliation included. The explanatory variables referring to FDI features are modelled as interactions by assigning them the value of 0 in case of non-MNEs 
Table 10 Nonresponse analysis: results of multi-level logit model (nonresponse $=1$ ) for Czech firms-estimated coefficients

\begin{tabular}{|c|c|c|c|}
\hline & 1 & 2 & 3 \\
\hline & Coefficients & Coefficients & Coefficients \\
\hline \multicolumn{4}{|l|}{ Firm characteristics } \\
\hline \multicolumn{4}{|l|}{ No. of employees 2010 (ref.: 50-99): } \\
\hline $1-5$ & $0.5436^{* * *}$ & $0.5471^{* * *}$ & $0.5184^{* * *}$ \\
\hline $6-9$ & 0.1398 & 0.1440 & 0.1267 \\
\hline $10-19$ & 0.1594 & 0.1690 & 0.1715 \\
\hline $20-49$ & 0.1146 & 0.1187 & 0.1171 \\
\hline 100-199 & $0.3732^{* *}$ & $0.3776^{* *}$ & $0.3832^{* *}$ \\
\hline $200-499$ & $0.6791^{* * *}$ & $0.6778^{* * *}$ & $0.6912^{* * *}$ \\
\hline 500-999 & $0.6138^{* *}$ & $0.6142^{* *}$ & $0.6192^{* *}$ \\
\hline $1000+$ & $1.5660^{* * *}$ & $1.5704^{* * *}$ & $1.5797^{* * *}$ \\
\hline Unknown & $1.3546^{* * *}$ & $1.3590^{* * *}$ & $1.3151^{* * *}$ \\
\hline MNE group (yes $=1$ ) & $-0.5280^{* * *}$ & $-0.5356^{* * *}$ & 0.1055 \\
\hline Distance to German border (in km, In) & $-0.3108^{* *}$ & $-0.2876^{* *}$ & $-0.2777^{* *}$ \\
\hline Border region Czech Republic (yes $=1$ ) & $-0.8196^{* * * *}$ & $-0.7366^{* * *}$ & $-0.7375^{* * *}$ \\
\hline \multicolumn{4}{|l|}{ Interviewer characteristics } \\
\hline Male (yes $=1$ ) & & 0.0244 & 0.0227 \\
\hline Interviewer age (in years) & & $-0.1232^{*}$ & $-0.1237^{*}$ \\
\hline Interviewer age (in years) squared & & 0.0008 & 0.0008 \\
\hline No. of assigned firms & & 0.0046 & 0.0046 \\
\hline \multicolumn{4}{|l|}{ FDI characteristics } \\
\hline Equity share (In) & & & $0.3578^{*}$ \\
\hline Direct investment (yes $=1$ ) & & & $-0.3262^{* *}$ \\
\hline Duration of investment (in years, In) & & & $-0.1868^{* *}$ \\
\hline Border region Germany (yes $=1$ ) & & & 0.0826 \\
\hline Const. & $3.5621^{* * *}$ & $7.1201^{* * *}$ & $7.0947^{* * *}$ \\
\hline Random part: intercept variance $\left(\zeta_{i}\right)$ & $2.2828^{* * *}$ & $1.8653^{* * *}$ & $1.8684^{* * *}$ \\
\hline ICC & 0.4096 & 0.3618 & 0.3622 \\
\hline No. of observations & 9162 & 9162 & 9162 \\
\hline Log likelihood & -2999.3667 & -2980.0121 & -2973.5426 \\
\hline
\end{tabular}

Significance level: ${ }^{*}<0.1,{ }^{* *}<0.05, * * * 0.01$. Control variables for industry affiliation included. The explanatory variables referring to FDI features are modelled as interactions by assigning them the value of 0 in case of non-MNEs 
Table 11 Nonresponse analysis: results of multi-level logit model (nonresponse $=1$ ) for German and Czech firmsestimated coefficients

\begin{tabular}{|c|c|c|c|}
\hline & 1 & & \\
\hline & Coefficients & Coefficients & Coefficients \\
\hline \multicolumn{4}{|l|}{ Firm characteristics } \\
\hline \multicolumn{4}{|l|}{ No. of employees 2010 (ref.: 50-99) } \\
\hline $1-5$ & 0.0793 & 0.0805 & 0.0440 \\
\hline $6-9$ & -0.1796 & -0.1733 & $-0.1995^{*}$ \\
\hline $10-19$ & -0.0913 & -0.0871 & -0.0941 \\
\hline $20-49$ & -0.0533 & -0.0498 & -0.0570 \\
\hline 100-199 & $0.2761^{* * *}$ & $0.2793^{* * *}$ & $0.2848^{* * *}$ \\
\hline 200-499 & $0.5004^{* * *}$ & $0.5013^{* * *}$ & $0.5070^{* * *}$ \\
\hline $500-999$ & $0.5754^{* * *}$ & $0.5799^{* * *}$ & $0.5900^{* * *}$ \\
\hline $1000+$ & $0.7929^{* * *}$ & $0.8063^{* * *}$ & $0.8451^{* * *}$ \\
\hline Unknown & $1.0957^{* * *}$ & $1.0975^{* * *}$ & $1.0427^{* * *}$ \\
\hline MNE group $($ yes $=1$ ) & 0.0982 & 0.1175 & $0.8768^{* * *}$ \\
\hline Distance to border (in km, ln) & $0.2492^{*}$ & $0.2931^{* *}$ & $0.3002^{* *}$ \\
\hline Border region domestic country (yes $=1$ ) & 0.1387 & 0.2255 & 0.2683 \\
\hline Czech firm (yes $=1$ ) & $3.5043^{* * *}$ & $2.6445^{* * *}$ & $2.6973^{* * *}$ \\
\hline Czech firm * MNE group (interaction term) & $-0.6109^{* * *}$ & $-0.6413^{* * *}$ & $-0.6107^{* * *}$ \\
\hline Czech firm * Distance to border (in km, In) (interaction term) & $-0.5752^{* * *}$ & $-0.5921^{* * *}$ & $-0.5994^{* * *}$ \\
\hline Czech firm * Border region (interaction term) & $-0.9949^{* *}$ & $-1.0324^{* *}$ & $-1.0541^{* * *}$ \\
\hline \multicolumn{4}{|l|}{ Interviewer characteristics } \\
\hline Male $($ yes $=1)$ & & 0.0130 & 0.0129 \\
\hline Interviewer age (in years) & & -0.0385 & -0.0399 \\
\hline Interviewer age (in years) squared & & 0.0001 & 0.0001 \\
\hline No. of assigned firms & & $-0.0062^{* *}$ & $-0.0061^{* *}$ \\
\hline Czech firm * No. of assigned firms (interaction term) & & $0.0119^{* * *}$ & $0.0119^{* * *}$ \\
\hline \multicolumn{4}{|l|}{ FDI characteristics } \\
\hline Equity share (In) & & & -0.0589 \\
\hline Czech firm * Equity share $(\mathrm{In})($ interaction term) & & & 0.3636 \\
\hline Direct investment (yes $=1$ ) & & & $-0.3881^{* * *}$ \\
\hline Duration of investment (in years, In) & & & $-0.2330^{* * *}$ \\
\hline Border region foreign country (yes $=1$ ) & & & -0.0879 \\
\hline Const. & 0.0612 & $2.0865^{* *}$ & $2.0872^{* *}$ \\
\hline Random part: intercept variance $\left(\zeta_{j}\right)$ & $1.6301^{* * *}$ & $1.4694^{* * *}$ & $1.4785^{* * *}$ \\
\hline ICC & 0.3313 & 0.3088 & 0.3101 \\
\hline No. of observations & 16,426 & 16,426 & 16,426 \\
\hline Log likelihood & -6185.6262 & -6158.4672 & -6143.684 \\
\hline
\end{tabular}

Significance level: ${ }^{*}<0.1,{ }^{* *}<0.05,{ }^{* * *}<0.01$. Control variables for industry affiliation included. The explanatory variables referring to FDI features are modelled as interactions by assigning them the value of 0 in case of non-MNEs

\section{Publisher's Note}

Springer Nature remains neutral with regard to jurisdictional claims in published maps and institutional affiliations.

Received: 11 July 2018 Accepted: 22 December 2018 Published online: 16 January 2019

\section{References}

Alfaro, L., Charlton, A.: Intra-industry foreign direct investment. Am. Econ. Rev. 99(5), 2096-2119 (2009)
Bermejo Carbonell, J., Werner, R.A.: Does foreign direct investment generate economic growth? A new empirical approach applied to Spain. Econ. Geogr. 94(4), 425-456 (2018)

Betriebsnummernservice der Bundesagentur für Arbeit: Betriebsnummernvergabe. https://con.arbeitsagentur.de/prod/apok/ct/dam/download/ documents/dok_ba015200.pdf (2018). Accessed 13 June 2018

Beullens, K., Loosveldt, G.: Interviewer effects in the European Social Survey. Surv. Res. Methods 10(2), 103-118 (2016)

Brüderl, J., Huyer-May, B., Schmiedeberg, C.: Interviewer behaviour and the quality of social network data. In: Winker, P., Menold, N., Porst, R. (eds.) Interviewers' deviations in surveys. Impact, reasons, detection and prevention, pp. 147-160. PL Academic Research, Frankfurt am Main (2013) 
Buch, C.M., Kleinert, J., Lipponer, A., Toubal, F.: Determinants and effects of foreign direct investment: evidence from german firm-level data. Econ. Policy 20(41), 52-110 (2005)

Campanelli, P., O'Muircheartaigh, C.: Interviewers, interviewer continuity, and panel survey nonresponse. Qual. Quant. 33(1), 59-76 (1999)

Crinò, R.: Offshoring, multinationals and labour market: a review of the empirical literature. J. Econ. Surv. 23(2), 197-249 (2009)

Deutsch-Tschechische Industrie- und Handelskammer (2008): Deutsche Unternehmen in Tschechien. Prag

Ellguth, P., Kohaut, S., Möller, I.: The IAB establishment panel—methodological essentials and data quality. J. Labour Mark. Res. 47(1), 27-41 (2014)

Fischer, G., Janik, F., Müller, D., Schmucker, A.: The IAB establishment panelthings users should know. Schmollers Jahrbuch 129(1), 133-148 (2009)

Groves, R.M.: Nonresponse rates and nonresponse bias in household surveys. Public Opin. Q. 70(5), 646-675 (2006)

Groves, R.M., Presser, S., Dipko, S.: The role of topic interest in survey participation decisions. Public Opin. Q. 68(1), 2-31 (2004)

Groves, R.M., Fowler, F.J., Couper, M.P., Lepkowski, J.M., Singer, E., Tourangeau, R.: Survey methodology. Wiley, Hoboken/New Jersey (2009)

Harkness, J.A., Van de Vijver, F.J.R., Johnson, T.P.: Questionnaire design in comparative research. In: Harkness, J.A., Van de Vijver, F.J.R., Mohler, PPh (eds.) Cross-cultural survey methods, pp. 19-34. wiley-interscience, Hoboken/ New Jersey (2003)

Hecht, V., Hohmeyer, K., Litzel, N., Moritz, M., Müller, J.-A., Phan thi Hong, V., Schäffler, J.: Motive, Strukturen und Auswirkungen deutscher Direktinvestitionen in Tschechien: Erste Untersuchungsergebnisse aus dem IABProjekt ReLOC - Research on Locational and Organisational Change. IAB Forschungsbericht 01/2013. http://doku.iab.de/forschungsbericht/2013/ fb0113.pdf (2013a). Accessed 03 July 2018

Hecht, V., Litzel, N., Schäffler, J.: The ReLOC project - method report for implementing a cross-border company survey in Germany and the Czech Republic. IAB Forschungsbericht 04/2013. http://doku.iab.de/forschungs bericht/2013/fb0413.pdf (2013b). Accessed 23 July 2018

Helpman, E.: Trade, FDI, and the organization of firms. J. Econ. Lit. 44(3), 589-630 (2006)

Helpman, E., Melitz, M.J., Yeaple, S.R.: Export versus FDI with heterogeneous firms. Am. Econ. Rev. 94(1), 300-316 (2004)

Janik, F., Kohaut, S.: Why don't they answer? Unit non-response in the IAB establishment panel. Qual. Quant. 46(3), 917-934 (2012)

Japec, L., Kreuter, F., Berg, M., Biemer, P., Decker, P., Lampe, C., Lane, J., O'Neil, C., Usher, A.: Big data in survey research-AAPOR Task Force Report. Public Opin. Q. 79(4), 839-880 (2015)

Jones, J.: Agglomeration economies and the location of foreign direct investment: a meta-analysis. J. Reg. Sci. 57(5), 731-757 (2017)

Josten, M., Trappmann, M.: Interviewer effects on a network-size filter question. J. Off. Stat. 32(2), 349-373 (2016)

Lechevalier, S.: Globalization and labor market outcomes: de-industrialization, job security, and wage inequalities-introduction by guest editor. Revi. World Econ. 151(3), 405-408 (2015)

Loosveldt, G., Beullens, K.:'How long will it take?' An analysis of interview length in the fifth round of the European Social Survey. Surv. Res. Methods 7(2), 69-78 (2013)

Möller, J., Litzel, N.: Measuring specialisation and concentration in regional clusters - an empirical analysis for Eastern Bavaria. In: Blien, U., Maier, G. (eds.) The economics of regional clusters, pp. 119-144. Elgar, Cheltenham (2008)

Nicolini, M., Resmini, L.: FDI spillovers in new EU member states. Econ. Transit. 18(3), 487-511 (2010)

Paul, J., Singh, G.: The 45 years of foreign direct investment research: approaches, advances and analytical areas. World Econ. 40(11), 2512-2527 (2017)

Petroni, R., Sigman, R., Willimack, D., Cohen, S., Tucker, C.: Response rates and nonresponse in establishment survey_BLS and Census Bureau. https:// www.bea.gov/about/pdf/Responseratesnonresponseinestablishments urveysFESAC121404.pdf (2004). Accessed 27 November 2017

Pflüger, M., Blien, U., Möller, J., Moritz, M.: Labor market effects of trade and FDI_recent advances and research gaps. Jahrbücher für Nationalökonomie und Statistik 233(1), 86-116 (2013)

Phipps, P. A., Jones, C. K.: Factors affecting response to the occupational employment statistics survey: Bureau of Labor Statistics. https://www.bls. gov/osmr/pdf/st070170.pdf (2007). Accessed 14 March 2018
Pickery, J., Loosveldt, G.: A multilevel multinomial analysis of interviewer effects on various components of unit nonresponse. Qual. Quant. 36(4), 427-437 (2002)

Rabe-Hesketh, S., Skrondal, A.: Multilevel and longitudinal modeling using Stata. Stata Press, College Station (2008)

Rogelberg, S.G., Stanton, J.M.: Introduction: understanding and dealing with organizational survey nonresponse. Organ. Res. Methods 10(2), 195-209 (2007)

Schäffler, J.: ReLOC Linkage: a new method for linking firm-level data with the establishment-level data of the IAB. FDZ-Methodenreport 05/2014 (en). http://doku.iab.de/fdz/reporte/2014/MR_05-14_EN.pdf (2014). Accessed 23 July 2018

Schäffler, J., Moritz, M.: German FDI in the Czech Republic-employment effects in the home country. IAB Discussion Paper 06/2018. http://doku. iab.de/discussionpapers/2018/dp0618.pdf (2018). Accessed 23 July 2018

Schnell, R.: Survey-Interviews. Methoden standardisierter Befragung. VS Verlag für Sozialwissenschaften, Wiesbaden (2012)

Smith, T.W.: Developing comparable questions in cross-national surveys. In: Harkness, J.A., Van de Vijver, F.J.R., Mohler, PPh (eds.) Cross-cultural survey methods, pp. 69-91. Wiley-Interscience, Hoboken/New Jersey (2003)

Snijders, T.A.B., Bosker, R.J.: Multilevel analysis. An introduction to basic and advance multilevel modeling. SAGE Publication Ltd, London (2012)

Thompson, K. J., Washington, K. T.: Challenges in the treatment of unit nonresponse for selected business surveys: a case study. Survey Methods: Insights from the Field. http://surveyinsights.org/?p=2991 (2013). Accessed 12 March 2018

Tomaskovic-Devey, D., Leiter, J., Thompson, S., Aldrich, R., Czaja, H., Kalleberg, A., Leicht, S., Perrow Mavrinak, C., Zimmer, C.: Organizational survey nonresponse. Adm. Sci. Q. 39(3), 439-457 (1994)

Van de Vijver, F.J.R., Leung, K.: Methods and data analysis for cross-cultural research. Sage Publications, Thousand Oaks/London/New Delhi (1997)

Wang, Y., Ning, L., Li, J., Prevezer, M.: Foreign direct investment spillovers and the geography of innovation in Chinese regions: the role of regional industrial specialization and diversity. Reg. Stud. 50(5), 805-822 (2016)

West, B.T., Blom, A.G.: Explaining interviewer effects: a research synthesis. J. Surv. Stat. Methodol. 5(2), 175-211 (2017)

West, B.T., Olson, K.: How much of interviewer variance is really nonresponse error variance? Public Opin. Q. 74(5), 1004-1026 (2010)

West, B.T., Kreuter, F., Jaenichen, U.: "Interviewer" effects in face-to-face surveys: a function of sampling, measurement error, or nonresponse? J. Off. Stat. 29(2), 277-297 (2013)

Wiengarten, L., Zwick, M.: Neue digitale Daten in der amtlichen Statistik. In: König, Ch., Schröder, J., Wiegand, E. (eds.) Big data: Chancen, Risiken, Entwicklungstendenzen, pp. 43-60. Springer, Wiesbaden (2018)

Williams, R.: Using the margins command to estimate and interpret predictions and marginal effects. Stata J. 12(2), 308-331 (2012)

Willimack, D.K., Nichols, E.: A hybrid response process model for business surveys. J. Off. Stat. 26(1), 3-24 (2010)

Willimack, D.K., Nicols, E., Sudman, S.: Understanding unit and item nonresponse in business surveys. In: Groves, R.M., Dillman, D.A., Eltinge, J.L., Littler, R.A. (eds.) Survey nonresponse, pp. 213-227. Wiley, New York (2002)

\section{Submit your manuscript to a SpringerOpen ${ }^{\odot}$ journal and benefit from:}

- Convenient online submission

- Rigorous peer review

- Open access: articles freely available online

- High visibility within the field

Retaining the copyright to your article

Submit your next manuscript at springeropen.com 